\title{
Cardiac CT scanning in coronary artery disease: Epicardial fat volume and its correlation with coronary artery lesions and left ventricular function
}

\author{
RUOHAN YIN, XIAOQIANG TANG, TAO WANG, HAIFENG SHI, \\ XIANG WANG, XIAOQIN WANG and CHANGJIE PAN \\ Department of Radiology, The Affiliated Changzhou No. 2 People's Hospital of Nanjing Medical University, \\ Changzhou, Jiangsu 213164, P.R. China
}

Received May 28, 2019; Accepted October 23, 2019

DOI: $10.3892 /$ etm.2020.9064

\begin{abstract}
Coronary artery disease (CAD) is a major and common disease that poses a threat to human health. Recent studies suggested that epicardial fat may have an important role in the pathogenesis of CAD. Therefore, the association between epicardial fat volume (EFV) and left ventricular function with CAD was investigated in the present study. A total of 61 patients with suspected CAD who underwent CT scanning were enrolled. Baseline data, parameters of left heart function and EFV of the subjects were collected and analyzed. The degree of coronary artery lesions was assessed using the Gensini score. Pearson's correlation analysis and a logistic regression model were applied to assess the association between EFV and risk factors for CAD, the Gensini score and left ventricular function index. A total of 29 female and 32 male subjects with a median age of 63 years were enrolled. The median body mass index (BMI) of the subjects was $23.37 \mathrm{~kg} / \mathrm{m}^{2}$ and the median EFV was $86.41 \mathrm{~cm}^{3}$. It was revealed that risk factors of $\mathrm{CAD}$, specially hypertension, diabetes mellitus, dyslipidemia, history of myocardial infarction and smoking, had no significant association with the EFV (P>0.05); however, the EFV was significantly positively correlated with the BMI $(r=0.479, \mathrm{P}<0.0001)$, interventricular septal thickness $(\mathrm{r}=0.436, \mathrm{P}=0.004)$, left ventricular posterior wall thickness $(\mathrm{r}=0.350, \mathrm{P}=0.0058)$, left ventricular end diastolic diameter $(\mathrm{r}=0.265, \mathrm{P}=0.0388)$, left ventricular mass $(\mathrm{r}=0.445, \mathrm{P}=0.0003)$ and left ventricular mass index $(\mathrm{r}=0.371$, $\mathrm{P}=0.0035)$. However, no correlation was identified between the EFV and the Gensini score $(\mathrm{r}=0.131, \mathrm{P}=0.3137)$. In conclusion,
\end{abstract}

Correspondence to: Dr Changjie Pan, Department of Radiology, The Affiliated Changzhou No. 2 People's Hospital of Nanjing Medical University, 68 Ge Hu Middle Road, Wu Jin, Changzhou, Jiangsu 213164, P.R. China

E-mail: changjiepan_pcj@163.com

Key words: cardiac computed tomography, epicardial fat volume, coronary artery disease, left ventricular function the EFV measured by cardiac CT scanning was positively correlated with the BMI and left ventricular function, but was not associated with the presence of CAD according to the Gensini scores.

\section{Introduction}

Coronary artery disease (CAD) is a frequent cardiovascular disease that is mainly caused by coronary atherosclerosis. It may result in arterial blood vessel stenosis, blockage or spasm, further leading to myocardial ischemia and hypoxia and/or a series of lesions (1-3). CAD may also cause further conditions, including angina pectoris, arrhythmia, heart failure or sudden death (4,5). Therefore, early diagnosis and treatment of CAD are of high clinical significance. In recent years, as medicine, science and technologies continue to progress and imaging technologies develop rapidly, the spatial and temporal resolution of CT scanning, which is widely used in the clinical diagnosis of CAD, have been markedly improved (6-8).

Adipose tissue, which is now considered as an endocrine organ, secretes various fat factors to affect the metabolism and certain pathological processes, including inflammation, oxidative stress and apoptosis $(9,10)$. Among adipocytokines, visfatin may be involved in the development of obesity-associated diseases, including diabetes and cardiovascular disease. Adiponectin is considered as an important anti-atherogenic and anti-diabetic protein and also as an anti-inflammatory protein (9). In recent years, the association between epicardial adipose tissue (EAT) and atherosclerosis has attracted increasing attention $(11,12)$. EAT is a specialized energy storage organ located between the myocardium and epicardium, which serve to provide energy (13-15). Previous studies have reported that EAT potentially causes local inflammation and may be seen as a marker for the risk of cardiovascular disease (16). Studies have indicated that EAT is an important risk factor for atherosclerotic diseases and metabolic syndrome $(17,18)$. The correlation between EAT and CAD has been previously reported; however, it is controversial whether EAT may be regarded as a marker to predict the occurrence and development of CAD (19-21). Therefore, in the present study, the epicardial fat volume (EFV) was measured by CT 
scanning to explore the correlation between the EFV and coronary artery lesions and left ventricular function, so as to provide a theoretical basis for the diagnosis of clinical CAD.

\section{Patients and methods}

Patient population. The present study was approved by the Medical Ethics Committee of The Affiliated Changzhou No. 2 People's Hospital of Nanjing Medical University (Changzhou, China) and all patients volunteered to participate in the present study and provided written informed consent. A total of 61 patients with known or suspected CAD who received cardiac CT scanning and coronary angiography at Changzhou No. 2 People's Hospital, the Affiliated Hospital of Nanjing Medical University (Changzhou, China) between December 2017 and October 2018 were enrolled. The inclusion criterion was as follows: One or more major coronary arteries with a diameter stenosis of $\geq 50 \%$. Patients with iodine contrast agent allergy, arrhythmias and hepatic and/or renal insufficiency were excluded. Those subjects who previously had a coronary artery operation or coronary bypass surgery, or those with respiratory diseases who cannot hold their breath for $>10 \mathrm{sec}$ were also excluded. The treatment of these patients mainly included administration of anti-hypertension drugs (amlodipine tablets, furosemide tables, spironolactone), statin drugs (pravastatin tablets, atorvastatin calcium tablets, rosuvastatin calcium tablets), anti-platelet agglutination drugs (aspirin enteric-coated tablet, clopidogrel hydrogen sulphate tablets) and nitrates (nitroglycerin tablet).

Data collection. Prior to CT scanning, the age, gender, family history of CAD, history of myocardial infarction, as well as smoking and drinking status of all participants were recorded. The body height and weight of the participants were measured to calculate the body mass index (BMI) and body surface area (BSA) as follows: BMI $\left(\mathrm{kg} / \mathrm{m}^{2}\right)=$ body weight $(\mathrm{kg}) /$ height $(\mathrm{m})^{2}$, BSA $\left(\mathrm{m}^{2}\right)=0.006 \mathrm{x}$ height $(\mathrm{cm})+0.013 \mathrm{x}$ body weight (kg)-0.153. A catheter-tipped micromanometer (SPC-454D, Millar Instrument Co.) and a polygraph system (RMC-2000; Nihon Kohden, Inc.), were used to measure and record the pulse pressure, systolic blood pressure (SBP) and diastolic blood pressure (DBP). Hypertension was defined as SBP $\geq 140 \mathrm{mmHg}$ and/or DBP $\geq 90 \mathrm{mmHg}$ or use of anti-hypertensive drugs. An automatic biochemistry analyzer (7060; Hitachi) was used to determine the levels of low-density lipoprotein-cholesterol (LDL-C), high-density lipoprotein-cholesterol (HDL-C), total cholesterol (TC) and fasting blood glucose (FBG). Dyslipidemia was defined as TC $>200 \mathrm{mg} / \mathrm{dl}$, LDL-C $\geq 130 \mathrm{mg} / \mathrm{dl}$ and HDL-C $<40 \mathrm{mg} / \mathrm{dl}$ for males or HDL-C $<50 \mathrm{mg} / \mathrm{dl}$ for females or those who used lipid-lowering medications. Diabetes mellitus was defined as FBG $\geq 126 \mathrm{mg} / \mathrm{dl}$ or treatment with hypoglycemic drugs.

Instruments and scanning methods. The CT examination equipment used in the present study was a 64-slice spiral CT scanner (SOMATOM Definition; Siemens AG) and the scanning parameters were as follows: Tube voltage, $120 \mathrm{kV}$; tube current, 90-160 mA; thread pitch, 0.2; slice thickness, 0.60-1.25 $\mathrm{mm}$; reconstruction thickness and reconstruction interval, $5 \mathrm{~mm}$. As the contrast media, Ultravist $(370 \mathrm{mg} \mathrm{I} / \mathrm{ml}$;
Schering AG) and Omnipaque (350 mgI/ml; GE Healthcare Ltd) at a volume of $60-80 \mathrm{ml}$ (scaled to body weight) was injected at $4.5-5.0 \mathrm{ml} / \mathrm{sec}$. After the injection, $40 \mathrm{ml}$ normal saline was injected at the same flow rate.

Measurement of EFV. After the scanning, the EFV data were analyzed using the Volume Viewer program (version 1.2.0.0) of the semi-automatic off-line workstation (Simens AG). The measurements were performed by two experienced radiologists who were blinded regarding the clinical condition of the patients (presence or absence of CAD). The pericardium was manually traced from the bifurcation of the pulmonary trunk to the last section containing any images of the heart to obtain a region of interest (ROI). The Hounsfield units (HU) threshold of -190 to $-30 \mathrm{HU}$ was used to isolate the fat content inside the ROI. The threshold value was visually adjusted by the radiologists to ensure that all adipose tissue in the pericardium was included (Fig. 1).

Assessment of the severity of CAD. Coronary angiography was performed on the patients by 64-slice multislice spiral CT. The degree of coronary artery stenosis was evaluated according to the coronary artery image evaluation criteria of the American Heart Association (22). The severity of CAD was based on the evaluation criteria of the Gensini scoring system (23) and analyzed by two experienced radiologists; a consensus was reached through discussion in the event of any disagreement. The degree of coronary artery stenosis was divided into groups of $25,50,75,90,99$ and $100 \%$, with corresponding scores of $1,2,4,8,16$ and 32 , respectively. The coronary arteries in different segments were multiplied by the corresponding coefficients as follows: Score x 5 for left major disease; score $\mathrm{x} 2.5$ for left anterior descending (LAD) proximal segment; score x1.5 for LAD middle segment; score $\mathrm{x} 1$ for LAD distal segment; score $\mathrm{x} 1$ for first diagonal branch; score $\mathrm{x} 0.5$ for second diagonal branch; score $\mathrm{x} 2.5$ for left circumflex artery (LCX) proximal segment, score $\mathrm{x} 1$ for LCX distal segment and posterior descending branch; score $\mathrm{x} 0.5$ for posterior lateral artery; score $\mathrm{x} 1$ for right coronary artery proximal, middle and distal segment and posterior descending branch. The final total integral was the sum of the integral of lesion branch, with a higher score indicating a more serious lesion degree.

Detection of left ventricular function. The participants underwent a complete transthoracic echocardiographic examination using the GE Vingmed System V (GE Healthcare) with a $3.5-\mathrm{MHz}$ phased-array probe. Three consecutive cycles were averaged for each parameter and analyzed by two cardiologists blinded to the data of the participants. Left ventricular end diastolic diameter (LVEDD), interventricular septal thickness (IVS), left ventricular posterior wall thickness (LVPW), left ventricular mass (LVM) and LVM index (LVMI) were measured and recorded according to the recommendations of the American Society of Echocardiography (24).

Statistical analysis. The statistical analysis was performed using SPSS version 20.0 (IBM Corp.). Kolmogorov-Smirnov test was used to assess normality of data distribution. The 
A

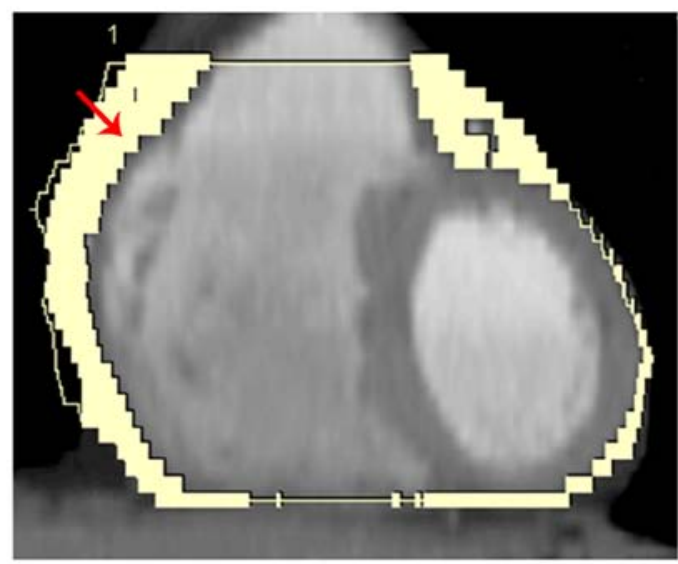

C

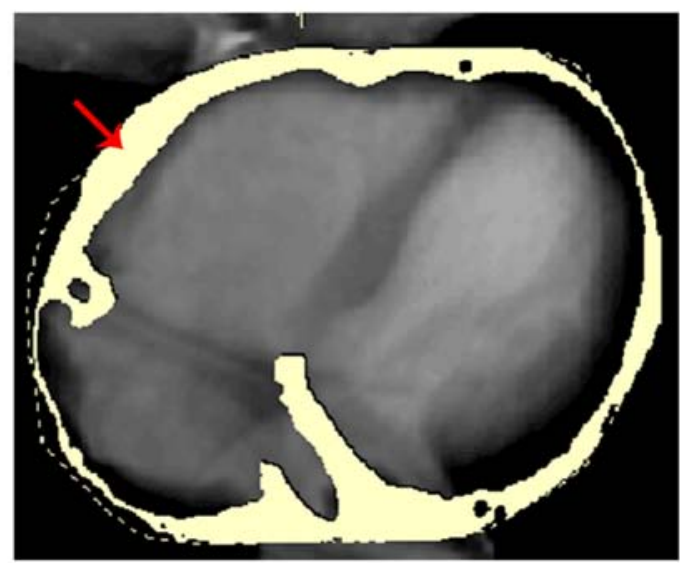

B

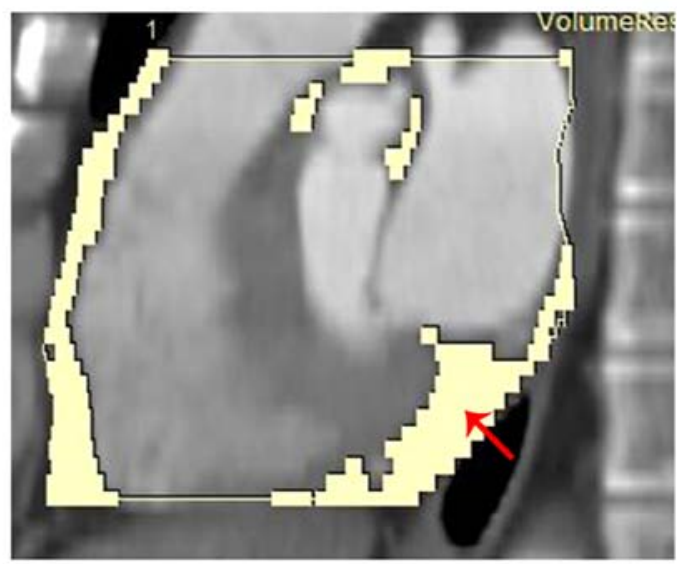

D

\begin{tabular}{|l|l|}
\hline Vol & \multicolumn{1}{|c|}{1} \\
\hline Volume [cm] & 137.50 \\
Height [cm] & 8.40 \\
Mean [HU] & -55.0 \\
SD [HU] & 47.6 \\
L Threshold [HU] & --- \\
U Threshold [HU] & --- \\
L Eval Limit [HU] & -250 \\
U Eval Limit [HU] & 30 \\
\hline
\end{tabular}

Figure 1. Measurement of EFV on CT. (A) Coronary image for determination of epicardial fat range. (B) Sagittal image for determination of epicardial fat range. (C) Cross-section image for determination of epicardial fat range. (D) The EFV of this subject with CAD was $137.50 \mathrm{~cm}^{3}$. A total of 61 patients with suspected CAD received cardiac CT scanning (64-slice spiral CT scanner; SOMATOM Definition; Siemens AG) and the EFV data were then analyzed using a Volume Viewer program of a semi-automatic off-line workstation (Simens AG). The range of fat density was -190 to -30 HU. The yellow area indicates the total volume of epicardial fat tissue distributed around the heart and arrows indicate the epicardial fat tissue. VOl, volume; L Eval Limit, lower evaluation limit; U Eval Limit, upper evaluation limit; HU, Hounsfield units; EFV, epicardial fat volume; CAD, coronary artery disease.

enumeration data were expressed as $\mathrm{n}(\%)$ and non-normally distributed data were expressed as the median and the 25 and 75th percentile quartiles (Q1 and Q3). The degrees of correlation between variables were determined by performing a Pearson's correlation analysis. Kruskal-Wallis analysis of variance was used to compare differences among the groups. $\mathrm{P}$-values were 2 -sided and a value of $\mathrm{P}<0.05$ was considered to indicate statistical significance.

\section{Results}

Clinical characteristics of the participants. The clinical characteristics of the participants are provided in Table I. A total of 61 patients with suspected CAD, including $29(52.5 \%)$ females and $32(47.5 \%)$ males, with a median age of 63 years (Q1 and Q3: 55 and 73 years), were selected as the research subjects in this study. The patients had a median BMI of $23.37 \mathrm{~kg} / \mathrm{m}^{2}$ (Q1 and Q3: 21.8 and $26.3 \mathrm{~kg} / \mathrm{m}^{2}$ ), a median BSA of $1.65 \mathrm{~m}^{2}$ (Q1 and Q3: 1.6 and $1.8 \mathrm{~m}^{2}$ ), a median pulse of 75 beats/min (Q1 and Q3: 69 and 88 beats/min), a median SBP of $130 \mathrm{mmHg}$ (Q1 and Q3: 120 and $146 \mathrm{mmHg}$ ) and a median DBP of $76 \mathrm{mmHg}(\mathrm{Q} 1$ and Q3: 70 and $88 \mathrm{mmHg})$. Among the 61 participants, $28(45.9 \%)$ had hypertension, $13(21.3 \%)$ had diabetes mellitus, 7 (11.5\%) had dyslipidemia and $2(3.3 \%)$ had a history of myocardial infarction. Regarding the smoking and drinking status of the participants, $11(18.0 \%)$ were current smokers and $6(9.8 \%)$ were former smokers, while $44(72.1 \%)$ had never smoked; furthermore, $5(8.2 \%)$ were drinkers and $56(91.8 \%)$ were non-drinkers. One participant $(1.6 \%)$ had a family history of CAD and the remaining 60 participants (98.4\%) did not have a family history of CAD. Among the 61 subjects, 43 patients $(70.5 \%)$ received medications and 18 (29.5\%) did not take any medications.

Association between EFV and risk factors for CAD. The distribution of EFV among the participants is provided in Fig. 2A and Table II; the median EFV among all participants was $86.41 \mathrm{~cm}^{3}$ (Q1 and Q3: 66.66 and $112.23 \mathrm{~cm}^{3}$ ). The median Gensini score among all participants was 4 (Q1 and Q3: 0 and 9). Table II provides the median EFV for subgroups based on the risk factors associated with CAD. In addition, the association between EFV and risk factors associated with CAD was evaluated, and it was revealed that hypertension, diabetes mellitus, dyslipidemia, history of myocardial infarction and smoking had no significant effect on the EFV $(\mathrm{P}>0.05)$. 
Table I. Basic data of the included subjects $(n=61)$.

\begin{tabular}{|c|c|}
\hline Characteristic & Value \\
\hline Age (years) & $63(55,73)$ \\
\hline \multicolumn{2}{|l|}{ Sex } \\
\hline Male & $32(52.5)$ \\
\hline Female & $29(47.5)$ \\
\hline BMI $\left(\mathrm{kg} / \mathrm{m}^{2}\right)$ & $23.37(21.8,26.3)$ \\
\hline $\operatorname{BSA}\left(\mathrm{m}^{2}\right)$ & $1.65(1.6,1.8)$ \\
\hline Pulse (beats/min) & $75(69,88)$ \\
\hline $\mathrm{SBP}(\mathrm{mmHg})$ & $130(120,146)$ \\
\hline $\mathrm{DBP}(\mathrm{mmHg})$ & $76(70,88)$ \\
\hline \multicolumn{2}{|l|}{ Coronary risk factor } \\
\hline Hypertension & $28(45.9)$ \\
\hline Diabetes mellitus & $13(21.3)$ \\
\hline Dyslipidemia & $7(11.5)$ \\
\hline History of myocardial infarction & $2(3.3)$ \\
\hline \multicolumn{2}{|l|}{ Smoking status } \\
\hline Current smoker & $11(18.0)$ \\
\hline Former smoker & $6(9.8)$ \\
\hline Never smoker & $44(72.1)$ \\
\hline \multicolumn{2}{|l|}{ Drinking status } \\
\hline Yes & $5(8.2)$ \\
\hline No & $56(91.8)$ \\
\hline \multicolumn{2}{|l|}{ Family history of CAD } \\
\hline Yes & $1(1.6)$ \\
\hline No & $60(98.4)$ \\
\hline \multicolumn{2}{|l|}{ Intake of medications } \\
\hline Yes & $43(70.5)$ \\
\hline No & $18(29.5)$ \\
\hline
\end{tabular}

Values are expressed as median (Q1, Q3) or n (\%). BMI, body mass index; BSA, body surface area; SBP, systolic blood pressure; DBP, diastolic blood pressure; CAD, coronary artery disease; Q1, first quartile; Q3, third quartile.

Correlation analysis. As provided in Fig. 2B-E, the Pearson's correlation analysis indicated that the EFV was significantly positively correlated with the BMI $(r=0.479, \mathrm{P}<0.0001)$, IVS $(\mathrm{r}=0.436, \mathrm{P}=0.004)$, LVPW $(\mathrm{r}=0.350, \mathrm{P}=0.0058)$, LVEDD $(\mathrm{r}=0.265, \mathrm{P}=0.0388), \mathrm{LVM}(\mathrm{r}=0.445, \mathrm{P}=0.0003)$ and $\mathrm{LVMI}$ $(\mathrm{r}=0.371, \mathrm{P}=0.0035)$. However, there was no significant correlation between the EFV and the Gensini score $(r=0.131$, $\mathrm{P}=0.31375$ ).

\section{Discussion}

CAD is a common disease seriously affecting human health and the risk factors include smoking, drinking, obesity, hypertension, dyslipidemia, diabetes mellitus, family history of CAD, history of myocardial infarction and/or abdominal fat accumulation (25-27). In addition to these factors, EAT has been reported to be involved in the pathogenesis of CAD (28). As an endocrine organ, EAT may directly affect the vascular
Table II. Association between EFV and risk factors of CAD.

\begin{tabular}{lrcc}
\hline Item/subgroup & $\mathrm{n}$ & EFV & P-value \\
\hline All patients & 61 & $86.41(66.66,112.23)$ & \\
Hypertension & & & 0.57 \\
$\quad$ Yes & 28 & $80.68(70.92,114.67)$ & \\
$\quad$ No & 33 & $90.12(58.69,109.67)$ & \\
Diabetes mellitus & & & 0.42 \\
$\quad$ Yes & 13 & $89.06(68.69,127.41)$ & \\
$\quad$ No & 48 & $85.52(66.34,106.28)$ & \\
Dyslipidemia & & & 0.96 \\
$\quad$ Yes & 7 & $76.73(71.23,89.06)$ & \\
$\quad$ No & 54 & $86.61(65.68,113.00)$ & \\
History of myocardial & & & 0.08 \\
infarction & & & \\
$\quad$ Yes & 2 & 60.15 & \\
$\quad$ No & 59 & $86.81(67.20,112.88)$ & \\
Smoking & & & \\
$\quad$ Current smoker & 11 & $71.41(66.22,112.88)$ & \\
Former smoker & 6 & $104.37(57.85,122.54)$ & \\
Never smoker & 44 & $86.61(66.83,105.74)$ & \\
\hline
\end{tabular}

Values are expressed as the median (Q1, Q3). P-values were calculated using Kruskal-Wallis analysis of variance; P-values were 2-sided and $\mathrm{P}<0.05$ was considered to indicate statistical significance. $\mathrm{Q} 1$, first quartile; Q3, third quartile; CAD, coronary artery disease; EFV epicardial fat volume.

wall and promote the progression of atherosclerosis by releasing inflammatory cytokines and mediators $(29,30)$. At present, the volume of epicardial fat may be determined by a variety of imaging techniques, including echocardiography, CT and cardiovascular magnetic resonance $(31,32)$. Due to its non-invasiveness, reliable results and capacity to provide abundant information, CT imaging technology is widely used in the detection of CAD and EAT $(33,34)$.

In the present study, CT scanning and standard methods were used to evaluate the degree of coronary artery lesions. It should be noted that in the present study, the association between EFV and clinical outcomes was not assessed, though it was attempted to analyze the association between the EFV and the severity of CAD. To date, the association between EAT and the severity of CAD has been under debate (35). In most studies, the EFV was proved to be significantly correlated with the Gensini score, suggesting that the EFV is closely associated with CAD $(36,37)$. Conversely, no correlation between the EFV and Gensini score was detected in the present study, which may be explained by the fact that only one patient in the study had a Gensini score of $>60$ (lack of critical patients). On the other hand, in the study by Tanami et al (38), a cohort of 320 patients with suspected CAD who underwent 320-detector row CT angiography exhibited a lack of association between the EFV and the presence and severity of CAD, which was similar to the present results. In addition, there are also certain differences between the present study and that of Tanami et al (38): In the present study, the correlation between 


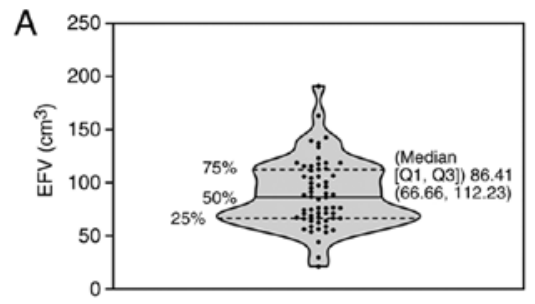

Distribution of epicardial fat volume in the study population.

B
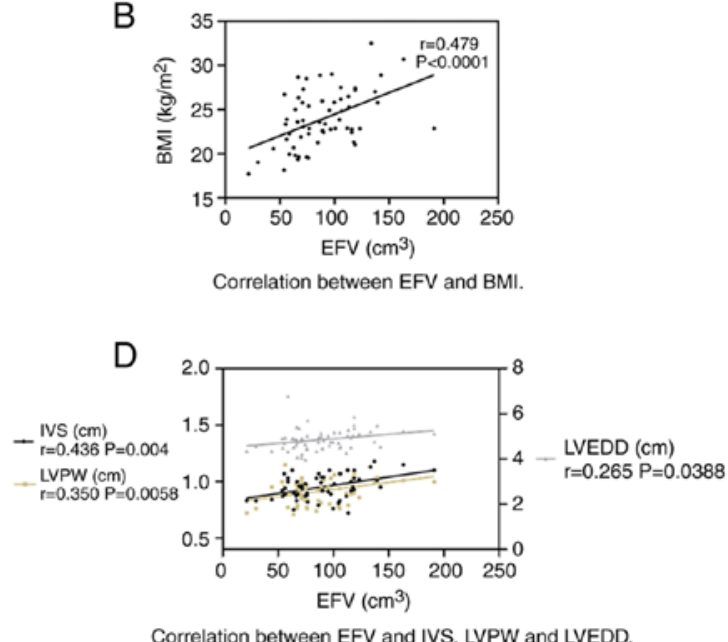

C

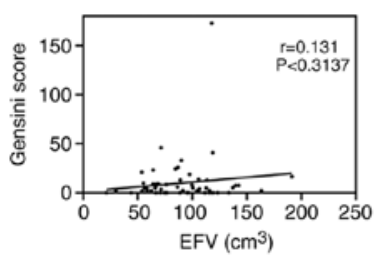

Correlation between EFV and Gensini score.

$\mathrm{E}$

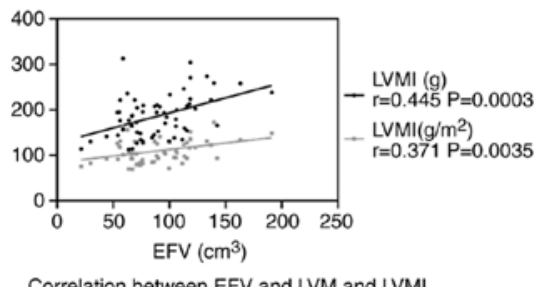

Figure 2. Association between EFV and left ventricular function analyzed by Pearson correlation analysis. (A) Violin plot indicating the distribution of EFV among the study participants; the median EFV was $86.84 \mathrm{~cm}^{3}$ (Q1 and Q3, 66.66 and $112.23 \mathrm{~cm}^{3}$, respectively). (B) Correlation between EFV and BMI $(r=0.479, P<0.0001)$. (C) Correlation between EFV and Gensini score $(r=0.131, P=0.3137)$. (D) Correlation between EFV and IVS ( $r=0.436, P=0.004), L V P W$ $(r=0.350, P=0.0058)$ and LVEDD $(r=0.265, P=0.0388)$. (E) Correlation between EFV and LVM ( $r=0.445, P=0.0003)$ and LVMI $(r=0.371, P=0.0035)$. EFV, epicardial fat volume; BMI, body mass index; IVS, interventricular septal thickness; LVPW, left ventricular posterior wall thickness; LVEDD, left ventricular end diastolic diameter; LVM, left ventricular mass; LVMI, LVM index; Q1, first quartile; Q3, third quartile.

the EFV and Gensini score was determined, while the latter study explored the correlation between EFV and the coronary calcification score.

It has been reported that the EFV was elevated with the increase of risk factors for CAD and was significantly associated with hypertension, diabetes, age and hyperlipidemia (39). Hell et al (40) determined the volume and density of EAT in CAD patients by using non-contrast CT, indicating that hypertension was the only risk factor affecting the volume and density of EAT. However, it has also been revealed that EAT is independent of traditional risk factors and contributes to fatal and non-fatal coronary events regardless of cardiovascular risk factors $(41,42)$. Hachiya et al (43) analyzed 134 patients who underwent multi-detector $\mathrm{CT}$ to assess them for CAD and observed that the increase in EFV was associated with augmented central aortic pressure and left ventricular diastolic dysfunction, but not with age, gender, hypertension, dyslipidemia, diabetes mellitus or prior myocardial infarction. In the present study, the risk factors for CAD, including hypertension, diabetes mellitus, dyslipidemia, history of myocardial infarction and smoking had no effect on the EFV. These conflicting results may be due to limitations of the measurement methods.

Overweight and obesity are important risk factors for CAD and the relevant evaluation indexes include BMI, waist circumference, hip circumference and percentage of body/visceral fat (44-46). EAT is a type of visceral fat with metabolic activity and is a source of multiple fat factors (47). Previous studies have indicated a direct association of EAT with the BMI and waist circumference $(48,49)$. In the present study, the EFV was positively correlated with the BMI, suggesting that with the increase of the EFV, the BMI and the risk of CAD were also increased. In addition, EFV was positively correlated with IVS, LVPW, LVEDD, LVM and LVMI. In the analysis of the association between EVF and left cardiac function, the indicators of left cardiac function adopted in the present study were different from those used in other studies $(50,51)$. Left ventricular dysfunction significantly increases the rate of mortality in CAD patients (52). Multiple studies have confirmed the correlation between EAT and LVM, left atrial size and left ventricular diastolic dysfunction (53-55), and this may be explained by the fact that the secretion of pro-inflammatory cytokines, free fatty acids and atherogenic cytokines by EAT may lead to arteriosclerosis (56). Vural et al (57) reported that patients with left ventricular diastolic dysfunction had a significantly increased EFV. Nerlekar et al (58) indicated that an increased EFV was associated with diastolic dysfunction. In addition, EAT is directly associated with the myocardium, may be subjected to local compressive forces and may affect the morphology and function of the heart by paracrine and mechanical interactions $(57,59)$. EAT induces inflammation by secreting a variety of adipokines and inflammatory factors, and persistent inflammation may lead to collagen deposition, thereby causing impaired left ventricular relaxation function and finally affecting the diastolic function of the left ventricle (58). Previous studies have reported that epicardial fat may increase the accumulation of myocardial triglycerides, 
which may cause apoptosis of myocardial cells, increase oxidative stress and damage of cardiac function $(60,61)$. In a state of cardiovascular disease, the EAT dilates, becoming hypoxic and dysfunctional and recruiting phagocytic cells, which may lead to increasing detrimental adipocytokines and eventually impaired cardiac function (61). In view of this, the $\mathrm{EFV}$ is correlated with the BMI and left ventricular function, which has certain clinical significance for the early diagnosis of diseases linked to obesity and left ventricular function.

The present study has certain limitations. For instance, the number of patients included in the study was small and patients with severe coronary artery lesions were not included in the study, as only 1 out of the 61 patients with suspected CAD had a Gensini score of $>60$. In the present study, the EFV was associated with left heart function, whereas poor left heart function is not a direct diagnostic basis for CAD, as coronary angiography remains the diagnostic gold standard for CAD (62). In addition, a previous study has indicated that abdominal adipose tissue was an important index for cardiovascular disease (63). Detection of abdominal adipose tissue may be more effective in fat evaluation and this will be our future research direction.

In conclusion, in the present study, the EFV determined using CT scanning was not associated with CAD based on the Gensini scores, but was positively correlated with the BMI, IVS, LVPW, LVEDD, LVM and LVMI. The association between EFV and BMI and left ventricular function still has certain clinical guiding significance. Further studies are required to determine the association between the EFV and coronary heart disease, and it may be suggested that the cohort size should be expanded or the evaluation indicators (e.g. the elasticity of ascending aorta) may be increased to enhance the reliability. In addition, the guiding significance of the EFV should be verified by examining the association between the EFV and heart diseases other than CAD. The association between the EFV and left ventricular diastolic function should be further explored and whether the location of epicardial fat affects left ventricular function also remains to be investigated.

\section{Acknowledgements}

Not applicable.

\section{Funding}

This work was supported by the Jiangsu Provincial Commission of Health and Family Planning Surface Project (grant no. H201658).

\section{Availability of data and materials}

The datasets used and/or analyzed during the current study are available from the corresponding author on reasonable request.

\section{Authors' contributions}

Substantial contributions to conception and design: RHY; data acquisition, data analysis and interpretation: XQT, TW, HFS, XW, XQW and CJP; drafting the article or critical revision for important intellectual content: RHY; final approval of the version to be published: All authors; agreement to be accountable for all aspects of the work to ensure that questions regarding the accuracy or integrity of the work are appropriately investigated and resolved: All authors.

\section{Ethics approval and consent to participate}

All procedures involving human participants were in accordance with the ethical standards of the institutional and/or national research committee and with the 1964 Helsinki declaration and its later amendments or comparable ethical standards. The present study was approved by the Medical Ethics Committee of The Affiliated Changzhou No. 2 People's Hospital of Nanjing Medical University (Changzhou, China) and all patients volunteered to participate in the present study and provided written informed consent.

\section{Patient consent for publication}

Not applicable.

\section{Competing interests}

The authors declare that they have no competing interests.

\section{References}

1. Potz BA, Parulkar AB, Abid RM, Sodha NR and Sellke FW: Novel molecular targets for coronary angiogenesis and ischemic heart disease. Coron Artery Dis 28: 605-613, 2017.

2. Marateb HR and Goudarzi S: A noninvasive method for coronary artery diseases diagnosis using a clinically-interpretable fuzzy rule-based system. J Res Med Sci 20: 214-223, 2015.

3. Olie RH, van der Meijden PEJ and Ten Cate H: The coagulation system in atherothrombosis: Implications for new therapeutic strategies. Res Pract Thromb Haemost 2: 188-198, 2018.

4. Goyal V, Jassal DS and Dhalla NS: Pathophysiology and prevention of sudden cardiac death. Can J Physiol Pharmacol 94: 237-244, 2016.

5. Zulkifli Amin H,Zulkifli Amin L and Zulkifli Amin F: Paramount importance of angiotensin receptor neprilysin inhibitor in heart failure management. Acta Med Iran 54: 823-824, 2016.

6. Han D, Lee JH, Hartaigh BO and Min JK: Role of computed tomography screening for detection of coronary artery disease. Clin Imaging 40: 307-310, 2016.

7. Dalager MG, Bøttcher M, Thygesen J, Andersen G and Bøtker HE: Different plaque composition and progression in patients with stable and unstable coronary syndromes evaluated by cardiac CT. Biomed Res Int 2015: 401357, 2015.

8. Saba L, Anzidei M, Piga M, Ciolina F, Mannelli L, Catalano C, Suri JS and Raz E: Multi-modal CT scanning in the evaluation of cerebrovascular disease patients. Cardiovasc Diagn Ther 4: 245-262, 2014

9. Matsuzawa Y: The metabolic syndrome and adipocytokines. Expert Rev Clin Immunol 3: 39-46, 2007.

10. Vidal H: Obesity and inflammation: The adipocytokines. Ann Endocrinol (Paris) 64: S40-S44, 2003 (In French).

11. Vacca M, Di Eusanio M, Cariello M, Graziano G, D'Amore S, Petridis FD, D'orazio A, Salvatore L, Tamburro A, Folesani $\mathrm{G}$, et al: Integrative miRNA and whole-genome analyses of epicardial adipose tissue in patients with coronary atherosclerosis. Cardiovasc Res 109: 228-239, 2016.

12. Fitzgibbons TP and Czech MP: Epicardial and perivascular adipose tissues and their influence on cardiovascular disease: Basic mechanisms and clinical associations. J Am Heart Assoc 3: e000582, 2014.

13. Yang TT, Fish AF, Kong WM, Gao X, Huang J, Feng JT, Zhu JY, Chen $T$ and Lou QQ: Correlates of pericardial adipose tissue volume using multidetector CT scanning in cardiac patients in China. Int J Cardiol 244: 285-289, 2017. 
14. Nagy E, Jermendy AL, Merkely B and Maurovich-Horvat P: Clinical importance of epicardial adipose tissue. Arch Med Sci 13: 864-874, 2017.

15. Kitagawa T, Yamamoto H, Sentani K, Takahashi S, Tsushima H, Senoo A, Yasui W, Sueda T and Kihara Y: The relationship between inflammation and neoangiogenesis of epicardial adipose tissue and coronary atherosclerosis based on computed tomography analysis. Atherosclerosis 243: 293-299, 2015.

16. Bertaso AG, Bertol D, Duncan BB and Foppa M: Epicardial fat: Definition, measurements and systematic review of main outcomes. Arq Bras Cardiol 101: e18-e28, 2013 (In English, Portuguese).

17. Fatma E, Bunyamin K, Savas S, Mehmet U, Selma Y, Ismail B, Sabri C, Gulzade O, Ibrahim D and Mehmet Y: Epicardial fat thickness in patients with rheumatoid arthritis. Afr Health Sci 15: 489-495, 2015.

18. Kocyigit I, Gungor O, Unal A, Yasan M, Orscelik O, Tunca O, Eroglu E, Sipahioglu MH, Tokgoz B, Ozdogru I, et al: A low serum free triiodothyronine level is associated with epicardial adipose tissue in peritoneal dialysis patients. J Atheroscler Thromb 21: 1066-1074, 2014.

19. Hartiala O, Magnussen CG, Bucci M, Kajander S, Knuuti J, Ukkonen H, Saraste A, Rinta-Kiikka I, Kainulainen S, Kähönen $\mathrm{M}$, et al: Coronary heart disease risk factors, coronary artery calcification and epicardial fat volume in the Young Finns Study. Eur Heart J Cardiovasc Imaging 16: 1256-1263, 2015.

20. Wu J, Zhang X, Li X and Yang L: Adipose tissue volume differences around the heart between subjects without coronary atherosclerosis and coronary heart disease patients. Acta Cardiol 71: 291-298, 2016.

21. Sironi AM, Petz R, De Marchi D, Buzzigoli E, Ciociaro D, Positano V, Lombardi M, Ferrannini E and Gastaldelli A: Impact of increased visceral and cardiac fat on cardiometabolic risk and disease. Diabet Med 29: 622-627, 2012.

22. Taylor AJ, Cerqueira M, Hodgson JM, Mark D, Min J, O'Gara P, Rubin GD; American College of Cardiology Foundation Appropriate Use Criteria Task Force; Society of Cardiovascular Computed Tomography; American College of Radiology, et al: ACCF/SCCT/ACR/AHA/ASE/ASNC/NASCI/SCAI/SCMR 2010 appropriate use criteria for cardiac computed tomography A report of the American College of Cardiology Foundation appropriate use criteria task force, the society of cardiovascular computed tomography, the American College of Radiology, the American Heart Association, the American Society of Echocardiography, the American Society of Nuclear Cardiology, the North American Society for cardiovascular imaging, the society for cardiovascular angiography and interventions, and the society for cardiovascular magnetic resonance. J Am Coll Cardiol 56: 1864-1894, 2010.

23. Gensini GG: A more meaningful scoring system for determining the severity of coronary heart disease. Am J Cardiol 51: 606, 1983.

24. Schiller NB, Shah PM, Crawford M, DeMaria A, Devereux R, Feigenbaum H, Gutgesell H, Reichek N, Sahn D, Schnittger I, et al: Recommendations for quantitation of the left ventricle by two-dimensional echocardiography. American Society of Echocardiography Committee on standards, subcommittee on quantitation of two-dimensional echocardiograms. J Am Soc Echocardiogr 2: 358-367, 1989.

25. Wang G, Li Y, Peng Y, Tang J and Li H: Association of polymorphisms in MALAT1 with risk of coronary atherosclerotic heart disease in a Chinese population. Lipids Health Dis 17: 75, 2018.

26. Hajar R: Diabetes as 'coronary artery disease risk equivalent': A historical perspective. Heart Views 18: 34-37, 2017.

27. Florido R, Zhao D, Ndumele CE, Lutsey PL, McEvoy JW, Windham BG, Pankow JS, Guallar E and Michos ED: Physical activity, parental history of premature coronary heart disease, and incident atherosclerotic cardiovascular disease in the atherosclerosis risk in communities (ARIC) study. J Am Heart Assoc 5: e003505, 2016.

28. Aydin AM, Kayali A, Poyraz AK and Aydin K: The relationship between coronary artery disease and pericoronary epicardial adipose tissue thickness. J Int Med Res 43: 17-25, 2015.

29. Topaloglu O, Sayki Arslan M, Turak O, Ginis Z, Sahin M, Cebeci M, Ucan B, Cakir E, Karbek B, Ozbek M, et al: Three noninvasive methods in the evaluation of subclinical cardiovascular disease in patients with acromegaly: Epicardial fat thickness, aortic stiffness and serum cell adhesion molecules. Clin Endocrinol (Oxf) 80: 726-734, 2014.

30. Tanaka $\mathrm{K}$ and Sata M: Roles of perivascular adipose tissue in the pathogenesis of atherosclerosis. Front Physiol 9: 3, 2018.
31. Izgi C: Epicardial adipose tissue: Just a predictor or a local player for coronary atherosclerosis? Anatol J Cardiol 15: 360-362, 2015.

32. Douglass E, Greif S and Frishman WH: Epicardial fat: Pathophysiology and clinical significance. Cardiol Rev 25: 230-235, 2017.

33. Yuce G, Türkvatan A and Yener Ö: Can aortic atherosclerosis or epicardial adipose tissue volume be used as a marker for predicting coronary artery disease? J Cardiol 65: 143-149, 2015.

34. Romijn MA, Danad I, Bakkum MJ, Stuijfzand WJ, Tulevski II, Somsen GA, Lammertsma AA, van Kuijk C, van de Ven PM, Min JK, et al: Incremental diagnostic value of epicardial adipose tissue for the detection of functionally relevant coronary artery disease. Atherosclerosis 242: 161-166, 2015.

35. Kim SH, Chung JH, Kwon BJ, Song SW and Choi WS: The associations of epicardial adipose tissue with coronary artery disease and coronary atherosclerosis. Int Heart J 55: 197-203, 2014.

36. Ghaderi F, Eshraghi A, Shamloo AS and Mousavi S: Assosiation of epicardial and pericardial fat thickness with coronary artery disease. Electron Physician 8: 2982-2989, 2016.

37. Yang C, Li L, Zha Y and Peng Z: Correlation between epicardial adipose tissue and severity of coronary artery stenosis evaluated by 64-MDCT. Clin Imaging 40: 477-480, 2016.

38. Tanami Y, Jinzaki M, Kishi S, Matheson M, Vavere AL, Rochitte CE, Dewey M, Chen MY, Clouse ME, Cox C, et al: Lack of association between epicardial fat volume and extent of coronary artery calcification, severity of coronary artery disease, or presence of myocardial perfusion abnormalities in a diverse, symptomatic patient population: Results from the CORE320 multicenter study. Circ Cardiovasc Imaging 8: e002676, 2015.

39. Bo X, Ma L, Fan J, Jiang Z, Zhou Y, Zhang L and Li W: Epicardial fat volume is correlated with coronary lesion and its severity. Int J Clin Exp Med 8: 4328-4334, 2015.

40. Hell MM, Ding X, Rubeaux M, Slomka P, Gransar H, Terzopoulos D, Hayes S, Marwan M, Achenbach S, Berman DS and Dey D: Epicardial adipose tissue volume but not density is an independent predictor for myocardial ischemia. J Cardiovasc Comput Tomogr 10: 141-149, 2016.

41. Hajsadeghi F, Nabavi V, Bhandari A, Choi A, Vincent H, Flores F, Budoff $M$ and Ahmadi N: Increased epicardial adipose tissue is associated with coronary artery disease and major adverse cardiovascular events. Atherosclerosis 237: 486-489, 2014.

42. Mahabadi AA, Berg MH, Lehmann N, Kälsch H, Bauer M, Kara K, Dragano N, Moebus S, Jöckel KH, Erbel R and Möhlenkamp S: Association of epicardial fat with cardiovascular risk factors and incident myocardial infarction in the general population: The Heinz Nixdorf Recall Study. J Am Coll Cardiol 61: 1388-1395, 2013.

43. Hachiya K, Fukuta H, Wakami K, Goto T, Tani T and Ohte N: Relation of epicardial fat to central aortic pressure and left ventricular diastolic function in patients with known or suspected coronary artery disease. Int J Cardiovasc Imaging 30: 1393-1398, 2014.

44. Sinha SK, Thakur R, Jha MJ, Goel A, Kumar V, Kumar A, Mishra V, Varma CM, Krishna V, Singh AK and Sachan M: Epicardial adipose tissue thickness and its association with the presence and severity of coronary artery disease in clinical setting: A cross-sectional observational study. J Clin Med Res 8: 410-419, 2016.

45. Antonopoulos AS, Oikonomou EK, Antoniades C and Tousoulis D: From the BMI paradox to the obesity paradox: The obesity-mortality association in coronary heart disease. Obes Rev 17: 989-1000, 2016.

46. Sharma S, Batsis JA, Coutinho T, Somers VK, Hodge DO, Carter RE, Sochor O, Kragelund C, Kanaya AM, Zeller M, et al: Normal-weight central obesity and mortality risk in older adults with coronary artery disease. Mayo Clin Proc 91: 343-351, 2016.

47. Sequeira DI, Ebert LC, Flach PM, Ruder TD, Thali MJ and Ampanozi G: The correlation of epicardial adipose tissue on postmortem CT with coronary artery stenosis as determined by autopsy. Forensic Sci Med Pathol 11: 186-192, 2015.

48. Shaheen S, Hassan N, Awan M, Zehra N and Manzoor A: Epicardial adipose tissue (EAT) thickness and its association with BMI and waist circumference in healthy adults and coronary artery disease (CAD) patients. Br J Med Med Res 11: 1-10, 2016.

49. Iacobellis G, Mohseni M, Bianco SD and Banga PK: Liraglutide causes large and rapid epicardial fat reduction. Obesity (Silver Spring) 25: 311-316, 2017. 
50. Fontes-Carvalho R, Fontes-Oliveira M, Sampaio F, Mancio J Bettencourt N, Teixeira M, Rocha Gonçalves F, Gama V and Leite-Moreira A: Influence of epicardial and visceral fat on left ventricular diastolic and systolic functions in patients after myocardial infarction. Am J Cardiol 114: 1663-1669, 2014.

51. Ng AC, Goo SY, Roche N, van der Geest RJ and Wang WY: Epicardial adipose tissue volume and left ventricular myocardial function using 3-dimensional speckle tracking echocardiography. Can J Cardiol 32: 1485-1492, 2016.

52. Wang Y, Ma H, Hao X, Yang J, Chen Q, Lu L and Zhang R: Low serum calcium is associated with left ventricular systolic dysfunction in a Chinese population with coronary artery disease. Sci Rep 6: 22283, 2016.

53. Topuz M and Dogan A: The effect of epicardial adipose tissue thickness on left ventricular diastolic functions in patients with normal coronary arteries. Kardiol Pol 75: 196-203, 2017.

54. Kırış A, Kırış G, Turan OE, Öztürk M, Şahin M, İlter A, Bektaş O, Kutlu M, Kaplan SS and Gedikli Ö: Relationship between epicardial fat tissue and left ventricular synchronicity: An observational study. Anatol J Cardiol 15: 990-994, 2015.

55. Bakkum MJ, Danad I, Romijn MA, Stuijfzand WJ, Leonora RM, Tulevski II, Somsen GA, Lammertsma AA, van Kuijk C, van Rossum AC, et al: The impact of obesity on the relationship between epicardial adipose tissue, left ventricular mass and coronary microvascular function. Eur J Nucl Med Mol Imaging 42: 1562-1573, 2015.

56. Doğan M, Turak O, Akyel A, Grboviç E, Mendi MA, Oksüz F, Doğan A, Cimen T, Bilgin M, Sunman H, et al: Increased epicardial adipose tissue thickness is linked to aortic stiffness in patients with primary hypertension. Blood Press 23: 222-227, 2014.

57. Vural M, Talu A, Sahin D, Elalmis OU, Durmaz HA, Uyanık S and Dolek BA: Evaluation of the relationship between epicardial fat volume and left ventricular diastolic dysfunction. Jpn J Radiol 32: 331-339, 2014.
58. Nerlekar N, Muthalaly RG, Wong N, Thakur U, Wong DTL, Brown AJ and Marwick TH: Association of volumetric epicardial adipose tissue quantification and cardiac structure and function. J Am Heart Assoc 7: e009975, 2018.

59. Fernandes-Cardoso A, Santos-Furtado M, Grindler J, Ferreira LA, Andrade JL and Santo MA: Epicardial fat thickness correlates with P-wave duration, left atrial size and decreased left ventricular systolic function in morbid obesity. Nutr Metab Cardiovasc Dis 27: 731-738, 2017.

60. Kankaanpää M, Lehto HR, Pärkkä JP, Komu M, Viljanen A, Ferrannini E, Knuuti J, Nuutila P, Parkkola R and Iozzo P: Myocardial triglyceride content and epicardial fat mass in human obesity: Relationship to left ventricular function and serum free fatty acid levels. J Clin Endocrinol Metab 91: 4689-4695, 2006.

61. Lin HH, Lee JK, Yang CY, Lien YC, Huang JW and Wu CK: Accumulation of epicardial fat rather than visceral fat is an independent risk factor for left ventricular diastolic dysfunction in patients undergoing peritoneal dialysis. Cardiovasc Diabetol 12: 127, 2013.

62. Peng-Hui Jian L-FX and Tie-Jun Zhang: Study on ultrasound evaluation of carotid atherosclerosis and its predicting value for coronary heart disease. 22 12: 4, 2016.

63. Neeland IJ, Ayers CR, Rohatgi AK, Turer AT, Berry JD, Das SR, Vega GL, Khera A, McGuire DK, Grundy SM and de Lemos JA: Associations of visceral and abdominal subcutaneous adipose tissue with markers of cardiac and metabolic risk in obese adults. Obesity (Silver Spring) 21: E439-E447, 2013.

(i)@( This work is licensed under a Creative Common International (CC BY-NC-ND 4.0) License. 